\title{
ANALYSIS OF GREYWATER SAMPLES TREATED BY FILTRATION
}

\author{
Csaba UNGVÁRI ${ }^{1}$, Andrea IZBÉKI-SZABOLCSIK², Ildikó BODNÁR ${ }^{3}$ \\ University of Debrecen, Faculty of Engineering, Department of Environmental Engineering, Debrecen, Hungary \\ ${ }^{1}$ csaba.ungvari31@gmail.com, \\ ${ }^{2}$ szabolcsikandi@eng.unideb.hu \\ ${ }^{3}$ bodnari@eng.unideb.hu
}

\begin{abstract}
In our research we pre-treated synthetically produced greywaters with filtration on various filters. We characterised the quality of greywater samples using several parameters. We investigated these parameters on the untreated and pre-treated samples as well. We evaluated the efficiency of the treatments by measuring the characteristic parameters. It was shown that the most effective pre-treatment for the greywater's preparation for reuse is filtration on silica sand or activated charcoal and silica sand combined filter media.
\end{abstract}

Keywords: greywater, reuse, artificial bathwater, filtration.

\section{Introduction}

Our freshwater supplies are finite, so the intensifying water shortage is an increasingly global problem. The problem is further aggravated by the fact that some freshwater locations are contaminated by anthropogenic or natural causes and can only be utilized using appropriate treatment technologies. Due to the development of technologies our water demand is constantly increasing in parallel with our energy needs, so the problem is further intensified. Professionals are striving to solve and mitigate this problem. For example, by cleaning contaminated water sources or desalination of salty seawater, another alternative source of water can be gathered, but the increase in water shortages is greater than the results of these efforts [1]. Beyond that, alternative water sources can also be the treatment and reuse of generated greywater in households.

\section{The greywater}

Greywaters are household wastewaters that are generated during bathing, washing and cooking activities and these waters do not contain sew- age from the toilet flush. The average wastewater discharge per person is 150-250 litres per day, of which the amount of greywater is $75-90 \%$, depending on, for example, how water-saving toilets are installed in the building. In Europe, the quantity of generated greywater varies between 35 and 150 litres per person per day [2]. If treated greywater is used, for example for toilet flushing, daily water consumption could be reduced by $30 \%$ [3]. In Hungary the average water consumption is $100-110$ litres per person per day, which can be more in larger cities and in smaller towns it is between 50 and 70 litres per person per day [4].

In the international literature greywater can be divided into two main groups, which according to the degree of contamination can be light or dark types. Hereby, we can distinguish a less polluted type (light grey-water) and a more polluted (dark greywater) type. The so-called light grey-water fraction is the less polluted part of greywater, for example the bathwater that contains so-called detergents from soaps, shower gels and additionally fats from the skin, hair and body [5]. Greywater from washing and dishwashing (dark greywater) contains high concentrations of chemical sub- 
stances from dish soaps and washing powders, bleaches, fats, oils, clothing dyes, and nondegradable fabrics from clothing and food residues [2]. In previous studies at the Department of Environmental Engineering at the Faculty of Engineering, University of Debrecen it was found that the quality parameters of greywater resulting from bathing are the closest to the quality of drinking water and account for almost 50\% of all the domestic greywater produced $[4,6]$, therefore the treatment and analysis of this fraction was targeted.

\section{Material and methods}

A drinking water based synthetic bathwater with constant composition was developed in the course of previous studies at the Department of Environmental Engineering in the past years and we made and used it. This synthetic bathwater characterizes well the household generated greywater in its composition. Then, we treated the prepared artificial bathwater samples by mechanical sewage treatment method. We filtrated equal volumes of the artificial bathwater as pre-treatment through four types of filter media: a natural zeolite, sand bed, activated carbon and sand bed combined filter media and natural zeolite and sand bed combined filter. Figure 1 . shows the schematic drawing of our created pilot filter system.

We measured the following parameters in the qualification of untreated, treated bathwater and drinking water samples, too: $\mathrm{pH}$ values, turbidity, zeta potential value, conductivity (EC), biological oxygen demand value (BOD5), chemical oxygen demand value (COD), dissolved organic carbon value (DOC). After the qualification, we analysed these parameters and from their change we deducted our conclusions.

\section{Result of the research}

According to directives, the most important parameters for greywater reuse are the BOD5 (according to US regulations the maximum is 10 $\mathrm{mgL}^{-1}$ ), $\mathrm{pH}$ (within the ranges 6-9) and turbidity (average 2 NTU, maximum 5 NTU) [2, 7, 8]. For this reason, in this study the measured values of turbidity, $\mathrm{pH}$ and BOD5 are described in detail.

We present the effects of filter media on the composition of greywaters, with the help of the average results of the 4 measurement series.

The average $\mathrm{pH}$ value for untreated greywater samples was 7.74 based on the 4 measurement series. The filtering processes, in most cases, slightly increased this $\mathrm{pH}$ value. The highest change of $\mathrm{pH}$ value was detected after filtering on silica sand (8.09). The changes of $\mathrm{pH}$ values were not significant for the other filter media. The measured value after filtration on the zeolite layer was 7.91, on zeolite and silica sand combined filter media was 7.96. The activated charcoal and silica sand combined filter media decreased the $\mathrm{pH}$ value to 7.60 .

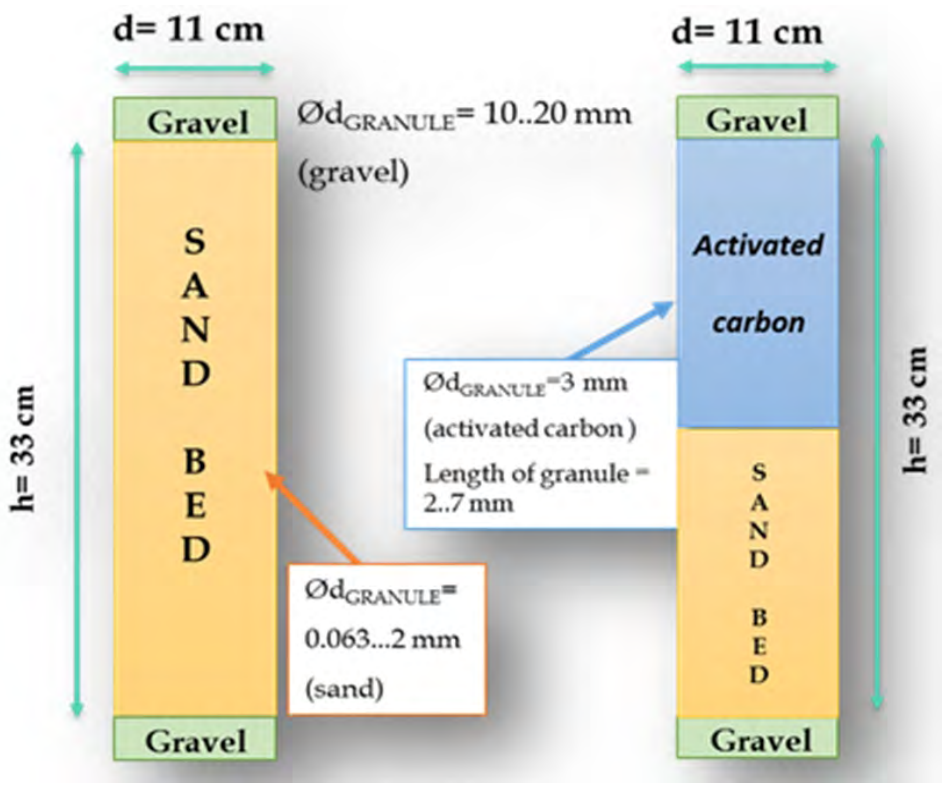

Figure 1. Schematic diagram of the filter system 
The average value of turbidity before filtration was $41.50( \pm 9.10)$ NTU. The turbidity values were significantly lower after filtration processing on different filter media. It was shown that the lowest decrease in turbidity values are detected after filtering on zeolite layer (22.06 $( \pm 7.78)$ NTU). The other three types of filter media decreased the turbidity significantly, for example the zeolite and silica sand combined filter media decreased the turbidity to $2.30( \pm 1.54) \mathrm{NTU}$, the silica sand layer $(1.56( \pm 0.24) \mathrm{NTU})$ and the activated charcoal and silica sand combined filter media (1.68 $( \pm 0.31)$ NTU) decreased the turbidity under the limit in above the guidelines (2 NTU).

To represent the organic compounds of greywater samples the most important parameter is the BOD5 values (maximum $10 \mathrm{mgL}^{-1}$ ) [8, 9]. In our research, the average BOD5 value for unfiltered greywater samples was $102.08( \pm 19.78) \mathrm{mgL}^{-1}$. During the filtrations, the BOD5 values were not decreased significantly, they were not reduced to below the limit in the guidelines. Moreover, during the filtration on the zeolite layer as a pre-treatment process, the average BOD5 value was increased to $168.73( \pm 24.71) \mathrm{mgL}^{-1}$. The filtration on the activated charcoal and silica sand combined filter media caused the highest decrease $\left(47.08( \pm 7.10) \mathrm{mgL}^{-1}\right)$ in organic content of samples.

\section{Conclusions}

With regard to the obtained results we can conclude the following:

- According to the above findings it can be seen that the two most important qualitative parameters of greywater samples are the turbidity and BOD5 values. It was shown that the turbidity values of samples was reduced to below the limit in the guidelines by filtration on the silica sand filter media and the combined filter media of activated charcoal and silica sand layer. The removal efficiency of insoluble agents was $48 \%$, $96 \%, 96 \%$ and $94 \%$ by using filtration treatment on natural zeolite, silica sand, activated charcoal and silica sand combined filter media, natural zeolite and silica sand combined filter media. Based on these data we can conclude that all of the filter media that we used, except the natural zeolite layer, removed most of the insoluble components, that caused turbidity.

- The various filter media were not able to reduce the BOD5 value below the limit value, therefore filtering can only be used as a pre-treatment process.
- The BOD5 value was reduced using all of the filter media, except the application of the natural zeolite layer. The increase can be explained by the contaminated filter media. The removal efficiency of organic content in BOD5 values was $29 \%, 51 \%$, and $19 \%$ by using the silica sand, activated charcoal and silica sand combined filter media; and the zeolite and silica sand combined filter media, respectively.

- The measured $\mathrm{pH}$ values of the filtered samples were 6-9 in all cases.

Alternatively, applying oxidative treatment may be a possible method of additional treatment, allowing us to reduce the BOD5 values to below 10 $\mathrm{mgL}^{-1}$ based on our preliminary studies. There is also an alternative additional treatment method, coagulation which, combined with filtration, is able to remove the organic and inorganic contaminants from greywater samples.

\section{Acknowledgments}

The publication is supported by the EFOP-3.6.1-162016-00022 project. The project is cofinanced by the European Union and the European Social Fund.

\section{References}

[1] United Nations: Water scarcity. 24 November 2014. (Accessed: 22 October 2017).

http://www.un.org/waterforlifedecade/scarcity. shtml.

[2] Ghaitidak D. M., Yadav K. D.: Characteristics and treatment of greywater $-A$ review. Environmental Science and Pollution Research, 20/5. (2013) 2795-2809.

https://doi.org/10.1007/s11356-013-1533-0

[3] Penn R., Schütze M., Friedler E.: Modelling the effects of on-site greywater reuse and low flush toilets on municipal sewer systems. Journal of environmental management, 114. (2013) 72-83. https://doi.org/10.1016/j.jenvman.2012.10.044

[4] Kalmár F. (ed.): Sustainable energy with the optimized integration of renewable energy sources. Chapter 5, Akadémiai Kiadó, Budapest, 167-201.

[5] Noah, M. (2002). Graywater use still a gray area. Journal of environmental health, 64(10), 22.

[6] Bodnar, I., Szabolcsik, A., Baranyai, E., Uveges, A., Boros, N.: Qualitative Characterization of the Household Greywater in Northern Great Plain Region of Hungary. Environmental Engineering and Management Journal 13/11. (2014) 2717-2724. https://doi.org/10.30638/eemj.2014.302

[7] Boyjoo Y., Pareek V. K., Ang M.: A review of greywater characteristics and treatment processes. Water Science and Technology, 67/7. (2013) 14031424.

https://doi.org/10.2166/wst.2013.675 
[8] Boros N., Szabolcsik A., Bodnár I.: Grey-water treatment and reuse possibilities in household. University of Debrecen, Proceedings of DENZERO International Conference, 2014, 193-200.

[9] Morel A., Diner S.: Greywater management in low and middle-income countries, review of different treatment systems for households or neighbourhoods. Sandec at Eawag, Dübendorf, Switzerland, 2006. 